\title{
Occupational therapy students' perspectives on the core competencies of graduates to practise in the field of neurology
}

\author{
L Jacobs-Nzuzi Khuabi, BSc (Occ Ther), MPH (Health Economics); J Bester, BOT, BSc Hons (Health Sciences), MPhil (Higher Education), \\ Postgrad Dipl (Program Monitoring and Evaluation); K Gatley-Dewing, BOT; S Holmes, BOT; C Jacobs, BOT; B Sadler, BOT; I van der Walt, BOT
}

Division of Occupational Therapy, Department of Health and Rehabilitation Sciences, Faculty of Medicine and Health Sciences, Stellenbosch University, Cape Town, South Africa

Corresponding author: L Jacobs-Nzuzi Khuabi (leeann@sun.ac.za)

\begin{abstract}
Background. The South African (SA) health system is characterised by limited resources, high bed turnover rates and a high therapist-to-patient ratio. Patients with neurological dysfunction form a large majority of the caseload of occupational therapists. Feedback from stakeholders alluded to some discrepancies between the content taught in the Stellenbosch University undergraduate curriculum and what is expected within the clinical setting. This raises questions regarding the relevance and applicability of what undergraduate occupational therapists are taught, given the nature and demands of the SA public health system.

Objective. To explore the perspectives of final-year occupational therapy students with regard to the core competencies required for optimal preparation of students for practice in the field of neurology.

Methods. This explorative study used three focus groups to obtain the perspectives of 18 final-year students who had experienced clinical placements in neurology. Information from the focus groups was transcribed and analysed thematically to determine the findings.

Results. Analysis of the data revealed four themes, i.e. core knowledge and skills; attitude; resource and time constraints in clinical areas; and factors influencing optimal learning experiences.

Conclusion. The curriculum should prepare students to be well equipped for the current climate of the profession. While the current neurology curriculum may be viewed as having some positive features, there are some aspects that need to be updated and revised. Key considerations to optimise learning include a more regular interface between clinical areas and the university, scheduling of teaching blocks, and applying relevant teaching methods.
\end{abstract}

Afr J Health Professions Educ 2017;9(1):39-43. DOI:10.7196/AJHPE.2017.v9i1.722

Patients with neurological dysfunction form a large proportion of the patient population treated in the healthcare system. ${ }^{[1]}$ Dysfunction has a large impact on patients' functioning, which necessitates treatment from an occupational therapist and, therefore, forms a substantial portion of occupational therapists' workload. Patients' limited access to therapy and the high patient turnover mean that occupational therapists need adequate knowledge, experience and problem-solving skills to enable independent functioning of their patients in the shortest possible time. ${ }^{[2]}$ Informal feedback from stakeholders (occupational therapy clinicians, students, and clinical educators) alluded to some discrepancies between the content taught in the Stellenbosch University (SU) undergraduate curriculum and what is expected within the clinical setting. This raises questions regarding the relevance and applicability of what undergraduate occupational therapists are taught, given the nature and demands of the South African (SA) public health system. It is important that training programmes align with the health needs and available resources, in this case specifically within the SA context. According to Freeme, ${ }^{[3]}$ the ideal curriculum should consider the development of knowledge and skills from the latest research, the available resources on the clinical platform, and input from relevant stakeholders. It is essential that the restricted time for the teaching of neurology should be dedicated to the most relevant knowledge and skills needed in practice. ${ }^{[3]}$

McCluskey ${ }^{[4]}$ and Unger and Hanekom ${ }^{[5]}$ conducted studies in the domain of curriculum development in the health sciences. McCluskey ${ }^{[4]}$ identified the following categories for development of the neurology curriculum: foundation studies; assessment; treatment; and the building of confidence. To encourage confidence in practice, it was suggested that students gain more practical experience in the classroom and clinical setting, and a more sound knowledge of contemporary scientific literature in the field of neurology. The study by Unger and Hanekom ${ }^{[5]}$ identified three essential criteria deemed appropriate for determining the core content of a revised undergraduate curriculum. Content should be included in the curriculum if it: (i) is relevant to the SA context; (ii) ensures safe and effective practice by first-line practitioners; and (iii) is evidence based.

Studies by Chiang et al. ${ }^{[6]}$ and Naidoo et al ${ }^{[7]}$ provide insight on students' perspectives with regard to their readiness for clinical practice. The findings of the first-mentioned study indicated that a negative clinical experience may cause students to feel overwhelmed. This is often linked to inadequate guidance from clinical supervisors (lack of clear expectations and communication, understanding of students' learning needs and limited feedback) and inadequate preclinical preparation (limited time to practise techniques and to refresh theoretical knowledge). ${ }^{[6]}$ The latter study found that the students' level of confidence to practise was directly related to their degree of enjoyment and their fieldwork experience. There were, however, some concerns with regard to the curriculum content, teaching methods, and relationships with the lecturer and clinical supervisors. ${ }^{[7]}$

An important consideration is to include all stakeholders (occupational therapy clinicians, students and educators, client groups, employers, and professional boards) when developing a new curriculum. ${ }^{[8]}$ Stakeholders 
could aid in developing the content, teaching methods, evaluation requirements, and the delivery of the curriculum.

The purpose of this article is to investigate the students' views on the core competencies needed by final-year occupational therapy students in the field of neurology. Competence is defined as a multidimensional and dynamic concept that includes more than knowledge - the understanding of knowledge, interpersonal skills, clinical skills, clinical judgement, problemsolving and technical skills. ${ }^{[9]}$ The students' views as stakeholders form part of a larger study conducted at SU, which furthermore investigates the views of clinicians and academics to inform the revision of the neurology curriculum.

\section{Methods}

An explorative approach within a qualitative paradigm was used to explore the perspectives of 4th-year undergraduate occupational therapy students regarding the core competencies needed to work in the field of neurology. Total population sampling was used.

Participants included 18 final-year occupational therapy undergraduate students at $\mathrm{SU}$ who had placements in neurology in their final clinical block in the 3rd year or first clinical block in the 4th year. The study population was representative of participants who had exposure to neurology within primary, secondary and tertiary levels of healthcare, and learners with special needs from the Department of Education. Table 1 displays each participant's clinical placement according to the sector, and the diagnosis that they were exposed to.

Data were gathered through the use of three focus groups discussions (5 - 7 participants per group), lasting $\sim 1$ hour each. The focus groups were conducted by the researchers, using a predetermined question guide. The questions focused on the students' perspectives of the core knowledge, skills, and attitude required for practising neurology. It also explored the resource constraints they experienced in the clinical placements and aspects they viewed as important in the revision of the neurology curriculum.

Burnard's ${ }^{[10]} 14$-step method of data analysis for semi-structured interviews was used. The audio-recordings from the focus groups were transcribed verbatim. Inductive coding was done using the Qualitative Data Analysis (QDA) Miner 4 analysis program (Provalis Research, Canada). ${ }^{[1]}$

Lincoln and Guba's ${ }^{[12]}$ model of trustworthiness for qualitative research was used to ensure rigour. Credibility was ensured by acknowledging and analysing the researchers own preconceptions of the topic and their experiences of the neurology curriculum for objectivity. The researchers also used investigator triangulation, member checking and peer checking. Transferability was obtained by thick description of procedures for data collection and analysis. For dependability, the data were coded twice, checking that codes correlated. Confirmability was ensured through investigator triangulation and reflexivity.

Ethical clearance was obtained from the SU Health Research Ethics Committee (ref. no. N14/09/118) and the SU Institutional Research and Planning Committee, which oversees ethics of research involving the student population. Permission was also obtained from the Undergraduate Programme Committee of the Division of Occupational Therapy, SU. Ethical principles were upheld by giving the participants a choice to participate and respecting their opinions during the focus group discussions. Confidentiality was ensured by allocating participants pseudonyms, and all transcribed data were kept on password-protected programs to which only the researchers have access.
Table 1. Participants' clinical placements according to sector and diagnosis to which they were exposed

\begin{tabular}{|c|c|c|}
\hline Participant & Sector & List of diagnoses exposed to \\
\hline 1 & $\begin{array}{l}\text { Health: secondary level of } \\
\text { care }\end{array}$ & CVA, spinal cord injuries \\
\hline 2 & Health: primary level of care & $\begin{array}{l}\text { Spinal cord injuries, } \\
\text { amputations, TB spine }\end{array}$ \\
\hline 3 & $\begin{array}{l}\text { Education: special needs } \\
\text { school }\end{array}$ & $\mathrm{CP}$, neuro-psych \\
\hline \multirow[t]{2}{*}{4} & Health: tertiary level of care & $\begin{array}{l}\text { Paediatric: CP, neuro-psych, } \\
\text { TB spine }\end{array}$ \\
\hline & $\begin{array}{l}\text { Health: secondary level of } \\
\text { care }\end{array}$ & CVA, spinal cord injuries \\
\hline 5 & $\begin{array}{l}\text { Health: secondary level of } \\
\text { care }\end{array}$ & $\begin{array}{l}\text { CVA, spinal cord injuries, } \\
\text { TB meningitis }\end{array}$ \\
\hline 6 & $\begin{array}{l}\text { Education: special needs } \\
\text { school }\end{array}$ & $\mathrm{CP}$ \\
\hline 7 & Health: primary level of care & $\begin{array}{l}\text { Spinal cord injuries, } \\
\text { amputations, TB spine }\end{array}$ \\
\hline 8 & Health: primary level of care & CVA, TB spine \\
\hline 9 & $\begin{array}{l}\text { Health: secondary level of } \\
\text { care }\end{array}$ & TB meningitis \\
\hline 10 & $\begin{array}{l}\text { Health: Secondary level of } \\
\text { care }\end{array}$ & CVA \\
\hline 11 & Health: primary level of care & CVA, TB spine \\
\hline \multirow[t]{2}{*}{12} & $\begin{array}{l}\text { Health: secondary level of } \\
\text { care }\end{array}$ & CVA, CP \\
\hline & $\begin{array}{l}\text { Education: special needs } \\
\text { school }\end{array}$ & $\mathrm{CP}$ \\
\hline 13 & $\begin{array}{l}\text { Health: secondary level of } \\
\text { care }\end{array}$ & CVA \\
\hline 14 & Health: tertiary level of care & $\begin{array}{l}\text { Paediatric: CP, neuro-psych, } \\
\text { TB spine }\end{array}$ \\
\hline 15 & Health: primary level of care & CVA \\
\hline 16 & Health: primary level of care & CVA \\
\hline \multirow[t]{2}{*}{17} & Health: tertiary level of care & $\begin{array}{l}\text { Paediatric: CP, neuro-psych, } \\
\text { TB spine }\end{array}$ \\
\hline & $\begin{array}{l}\text { Education: special needs } \\
\text { school }\end{array}$ & $\mathrm{CP}$ \\
\hline 18 & Health: tertiary level of care & CVA, TBI \\
\hline
\end{tabular}

\section{Results}

Analysis of the data revealed four themes that participants felt should be considered for inclusion when revising the curriculum (Fig. 1). These themes are: core knowledge and skills; attitude; resource and time constraints in clinical areas; and factors influencing optimal learning experiences.

\section{Theme 1: Core knowledge and skills}

This theme encompasses core generic knowledge about pathology, anatomy and practice models. It furthermore includes core knowledge and skills pertaining to occupational therapy-specific neurological assessment, treatment and knowledge of own, and other professions' scope and role within an interdisciplinary team. 


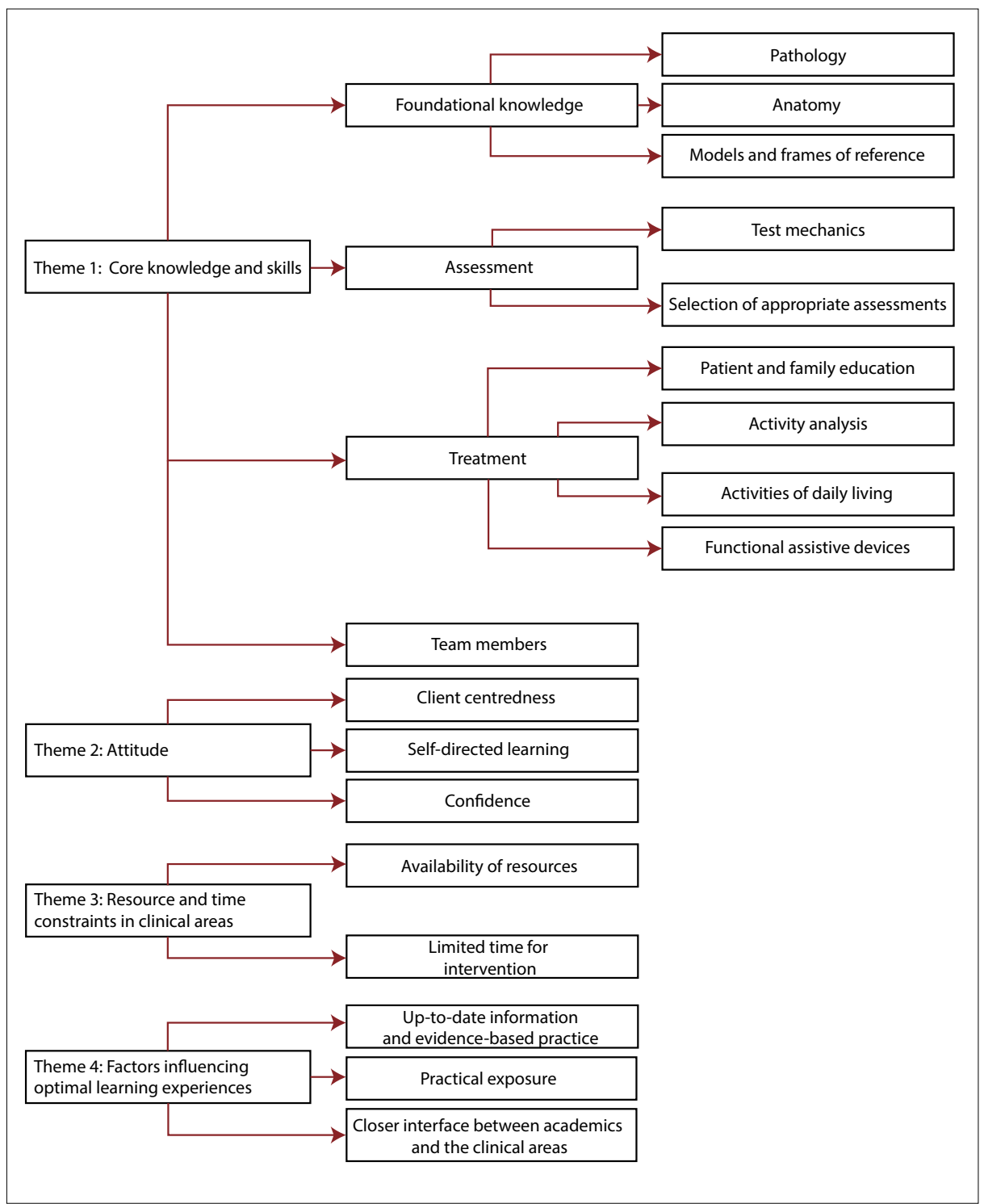

Fig. 1. Themes and categories that emerged from the data.

The majority of the participants felt that in terms of knowledge, the curriculum should include more information on core and trunk stability, spinal cord injury, and paediatrics, and that students need knowledge of models and frames of reference in the 1st year. The majority of the participants said that the current curriculum sufficiently prepares students for assessment, although there could be more focus on test mechanics. Participants thought that they should be better prepared for treatment, specifically activity analysis, which includes grading, how to make adaptations and how to integrate it within treatment. Participants thought it important to be taught the skill of making good use of time and prioritising intervention, which would help them to prepare for resource constraints of limited time with patients. They also felt that the knowledge of their own role and the scope of other team members' roles are important for clinical practice:

'The techniques we learn are good to know but ... we want to see how they are applied in the activity.

'In terms of spinal cord, because you have to make so many adaptations, you have to think very creative, to think if your patient can't supinate, how else is he going to dress himself ....'

'Communication skills with other professionals, especially, uhm, working with team members. It is really helpful to work with a physio.'
'We need to be taught how to do something in an hour, functionally and especially for the high turnover.'

\section{Theme 2: Attitude}

This theme alluded to the importance of client centredness, self-directed learning and confidence of the student.

Participants all agreed that confidence, adaptability and willingness to learn are essential attitudes for students to develop to ensure good clinical practice. It is suspected that having confidence may result in students being more handson in dealing with patients, thus improving the quality of service that they provide. Participants thought that the attitude of clinical therapists towards the curriculum and lecturers' attitudes towards the students are also important aspects to consider in the training of students in the field of neurology:

'I felt unsure and a little bit anxious, which automatically carries over to the patient and then the patient didn't want me to touch him and then that was not good at all.'

\section{Theme 3: Resource and time constraints in clinical areas}

This theme focused on the availability of resources within the clinical area and the limited time for intervention.

The greatest resource constraint identified by participants was limited time spent with patients owing to the high patient turnover, limited funds available to patients to attend outpatient services, and the scheduling of time for treatment, taking into consideration other team members:

'The reality of the high turnover I think is a very scary thing and it affects your therapy a lot more than you think it does and I didn't feel like we were equipped for that.'

'A resource constraint is, in terms of wheelchairs, a lot of the hospitals have a wheelchair shortage, and even the school I worked at.'

\section{Theme 4: Factors influencing optimal learning experiences}

This theme focused on the importance of evidence-based practice, practical exposure, and a closer interface between academics and the clinical areas.

The majority of participants felt that it would be beneficial to have neurology lectures scheduled consecutively, i.e. taught in a learning block. This would assist students to link aspects, allow- 
ing for better consolidation of the information. The participants alluded to the importance of making use of updated information sources and ensuring that the intervention taught is based on evidence-based practice. Participants indicated that using a variety of teaching methods, including case studies, videos and shared experiences, and being given an opportunity to observe the practical application of theory, can help to facilitate transference and application of what is taught from classroom to practice in the clinical setting. Participants felt that the opportunity to practise on real patients to develop skills is essential and that the mastering of skills takes place in the clinical setting. Participants also thought that there should be ongoing communication between the university, clinical platform, students and supervisors to ensure realistic expectations of students:

'That they clearly define what is undergraduate stuff and what they expect from us in a block because you come to the block and then they expect you to do postgrad stuff ... ?

'They give us unattached, separated pieces and they expect that when we get with our real patient all these puzzle pieces are going to come together.'

\section{Discussion}

Looking at the knowledge required for treatment, the participants did not feel adequately prepared for implementing appropriate treatment in the clinical setting. This may be because treatment knowledge is taught from the 3rd year when clinical practice has already commenced, while during the assessment of knowledge more time is allowed for learning, consolidation, and application, as it is taught in the 2 nd year. ${ }^{[13]}$ The participants also indicated that expectations for clinical practice differ from the theory that is taught in the classroom. It is speculated that this may be a contributing factor to why the participants do not feel adequately prepared for implementing treatment in clinical practice.

The prevailing point regarding the skills needed in practice was the participants' feeling that they did not have adequate opportunity for practising skills on real patients before commencing clinical practice. Many of the participants felt that as the mastering of skills occurs in the clinical setting, the opportunity for clinical practice is essential. This point needs to be considered when revising the neurology curriculum. It is important to view the grading of learning opportunities to facilitate the students from classroom experience to clinical practice. A possible grading could be as follows: students learn techniques in the classroom; they practise these on peers under supervision of the lecturer in class; they shadow the lecturer in the clinical field doing the techniques; and they have an opportunity in small groups to practise techniques on patients under supervision of the lecturer placed in a clinical setting.

Participants required more knowledge of the starting point for assessment and treatment. They felt it necessary to be skilled in working efficiently and prioritising intervention. Considering a change in the clinical picture and resource constraints, it is important for students to be innovative in creating solutions to problems. This raises the question of how to teach students to interpret referrals, taking cognisance of all the factors impacting on a particular patient. The greatest resource constraint experienced is having limited time with patients owing to high patient turnover, limited funds available to patients to attend outpatient services, and scheduling time for treatment, taking into consideration other team members. This is in line with the resource constraints expressed by Griffin. ${ }^{[14}$
It was stated that it is important for clinical supervisors to be understanding and have a positive attitude towards student supervision to improve the students' clinical experiences. This reflects what was found in the study by Chiang et al. ${ }^{[6]}$ which indicated that inadequate guidance by clinical lecturers often leads to a negative clinical experience.

Participants thought that being learning orientated will help to ensure that they are better prepared for clinical practice. As in other studies, ${ }^{[4,7]}$ participants in this study unanimously felt that confidence is an essential attitude when going into a clinical placement. The study by Naidoo et al..$^{[7]}$ found that students' experiences of clinical work directly relates to their degree of confidence in neurology practice.

Participants were of the opinion that transference and application of what is taught from theory to practice in the clinical setting could be facilitated by using teaching methods, such as case studies, videos, and lecturers sharing their clinical experience and demonstrating on real patients. It was suggested that it could be beneficial to teach the occupational therapy neurology curriculum together with the neurology content of preclinical subjects in a learning block, rather than spreading these out. This would allow greater opportunity for the students to be able to link all the aspects of the neurology practice together, allowing for better consolidation of the information.

\section{Conclusion}

This research suggests that the neurology curriculum should prepare students to be as well equipped as possible for the current climate of the profession in SA, and therefore should be updated and revised regularly. The majority of the participants recommended that neurology be taught as a learning block and that students should adopt a willingness to learn. Participants also felt that educators and therapists should maintain a positive attitude to facilitate the development of the students' confidence. Furthermore, clinical areas and the Division of Occupational Therapy should have clear communication to ensure alignment of what is taught and what is expected in clinical practice. While the current neurology curriculum may be viewed to have some positive features and aspects that need to be updated and revised, it may be valuable to note that, as pointed out by Tryssenaar and Perkins, ${ }^{[15]}$ that students will always perceive gaps and discrepancies in training, as it is difficult to teach all skills that may be needed in occupational therapy practice. Therefore, when revising an undergraduate curriculum, it is important for educators to consider the views of relevant stakeholders to determine the most important aspects for inclusion in the revision of a curriculum.

Acknowledgements. This research was funded by the Fund for Innovation and Research into Learning and Teaching (FIRLT), SU.

1. World Health Organization. The Global Burden of Disease. 2004 update. Geneva: WHO, 2004.

2. Wittman PP. The disparity between educational preparation and the expectations of the practice. Am J Occup Ther 1990;44(12):1130-1131. http://dx.doi.org/10.5014/ajot.44.12.1130

3. Freeme JD. A proposal for an undergraduate stroke rehabilitation curriculum appropriate for South African occupationl therapy. S Afr J Occup Ther 2014;44(1):69-75.

4. McCluskey A. Collaborative curriculum development: Clinicians' views on the neurology content of a new occupational therapy course. Aust Occup Ther J 2000;47(1):1-10.

5. Unger M, Hanekom SD. Benefits of curriculum renewal: The Stellenbosch University physiotherapy experience. Afr J Health Professions Educ 2014;6(2):222-226. http://dx.doi.org/10.7196/ajhpe.519

6. Chiang HYA, Pang CH, Li WS, Shih YN, Su CT. An investigation of the satisfaction and perception of fieldwork experiences among occupational therapy students. Hong Kong J Occup Ther 2012;22(1):9-16. http://dx.doi.org/ 10.1016/j.hkjot.2012.04.001

7. Naidoo D, van Wyk J, Joubert R. Are final-year occupational therapy students adequately prepared for clinical practice? A case study in KwaZulu-Natal. S Afr J Occup Ther 2014;44(3):24-28. http://dx.doi.org/10.7196/ ajhpe.2016.v811.536 
8. Rodger S, Clark M, Banks R, O'Brien M, Martinez K. A national evaluation of the Australian occupational therapy competency standards: A multistakeholder perspective. Aust Occup Ther J 2009;56(6):384-392. http:// dx.doi.org/10.1111/j.1440-1630.2009.00794.x

9. Verma S, Paterson M, Medves J. Core competencies for health care professionals: What medicine, nursing, occupationa therapy, and physiotherapy share. J Allied Health 2006;35(2):109-115.

10. Burnard P. A method of analysing interview transcripts in qualitative research. Nurse Educ Today 1991;11(6):461-466. http://dx.doi.org/10.1016/0260-6917(91)90009-y

11. Peledeau N. QDA Miner: User’s Guide. Montreal: Provalis Research, 2004.
12. Lincoln Y, Guba EG. Paradigmatic controversies, contradictions and emerging confluences revisited. In: Dezin NK, Lincoln YS. The Sage Handbook of Qualitative Research. 4th ed. Thousand Oaks, CA: Sage, 2011:97-128.

13. Stellenbosch University Occupational Therapy Department. Occupational Therapy Neurology Outcomes. Cape Town: Stellenbosch University, 2014.

14. Griffin SD. Short bed stays: Their effect on occupational therapy services in teaching hospitals. Arch Phys Med Rehabil 1993; 74:1087-1090

15. Tryssenaar J, Perkins J. From student to therapist: Exploring the first year of practice. Am J Occup Ther 2001;55(1):19-27. http://dx.doi.org/10.5014/ajot.55.1.19 